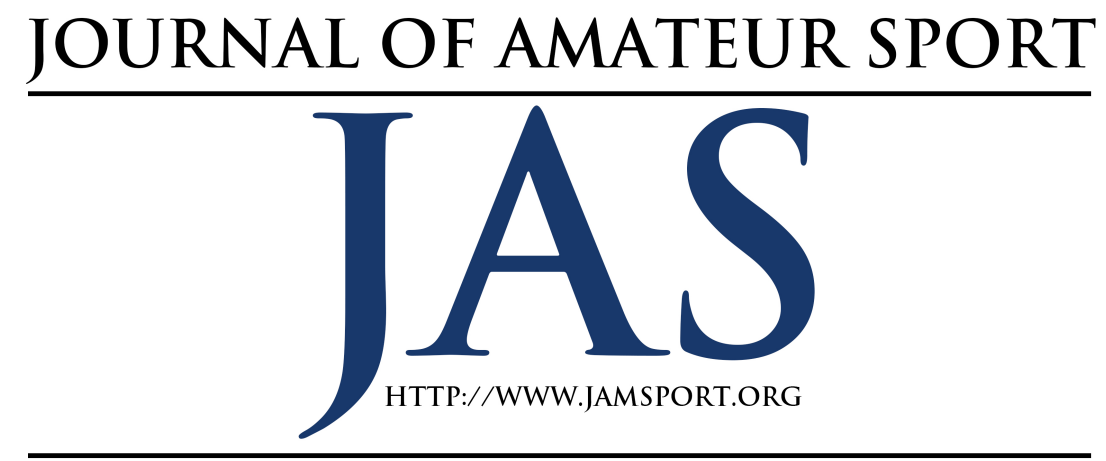

\title{
The Modernization of Policy-Making Processes in National Sport Organizations: A Case Study of Athletics Canada
}

\author{
Mathew Dowling ${ }^{1}$ \\ $\operatorname{Jim}_{\text {Denison }}^{2}$ \\ Marvin Washington ${ }^{2}$ \\ ${ }^{1}$ University of St. Mark and St. John \\ ${ }^{2}$ University of Alberta
}

\begin{abstract}
This article explores the consequences of modernization on the policy-making processes of a singular National Sport Organization: Athletics Canada. In drawing upon the works of Green and Houlihan (2005) as a baseline comparison, we examine how the organizations' policy-making processes have changed over a 10 -year period (2002-2012). Specifically, our analysis focuses on the nature and extent of these intraorganizational policy-related changes and how they have influenced the organization's decision-making capabilities. The descriptive analysis is informed by empirical data collected from eight in-depth semi-structured interviews with senior Athletics Canada personnel and concentrates on three inter-related themes (i) the development and prioritization of Own the Podium funded policies and programs; and (ii) the development and prioritization of evidence-based policies and programs, which, in turn, has resulted in (iii) increased inter-organizational relationship strain between Athletics Canada and its key delivery partners. More broadly, our investigation contributes to recent amateur sport scholarship that has sought to better understand how these broader socio-political shifts have influenced the specific decision-making processes of sport organizations.
\end{abstract}

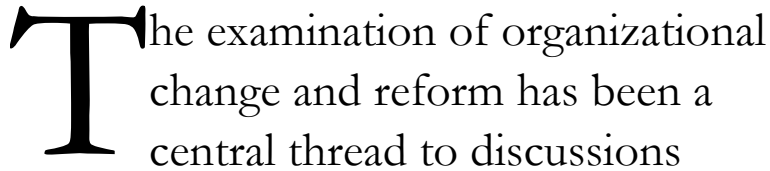

surrounding amateur sport. Scholars have drawn upon a raft of theoretical perspectives and concepts in order to understand and explain the nature and extent of change evident within amateur sport organizations. These include, but are not limited to, commercialization (e.g., 
Slack, 2004), professionalization (e.g., Thibault, Slack, \& Hinings, 1991; Macintosh, Bedecki, \& Franks, 1987; Macintosh \& Whitson, 1990), and organizational and institutional theory (e.g., O’Brien \& Slack, 2003, 2004; Kikulis, Slack, \& Hinings, 1992; Washington \& Patterson, 2011). Sport policy scholars have also drawn upon a number of meso-level theoretical concepts to explain organizational and systemic change. These include policy communities and advocacy coalitions (Green, 2004; Green \& Houlihan, 2005), lesson drawing and policy transfer (Green, 2007), and path-dependency (Green \& Collins, 2008). More recent discussions surrounding organization and systemic change have centred on more specific issues of corporate or organizational governance (e.g., Hoye \& Cuskelly, 2007; Shilbury \& Ferkins, 2011) and much broader concerns surrounding the modernization and the introduction of New Managerialism (NM) and New Public Management (NPM) into sport which are closely linked to what has collectively become known as the 'governance debate' (Rhodes, 1996; for its application to sport see Goodwin \& Grix, 2011; Grix, 2010; Grix \& Phillpots, 2011; Phillpots, Grix, \& Quarmby, 2011).

Within the Canadian sport context, recent reform of the amateur sport landscape in general and National Sport Organizations (NSOs), the national level sport organizations responsible for governing over specific sports, in particular has been underpinned by two major, inter- related developments. The first of which has been Canada's successful bid to host the 2010 Olympic Winter Games in Vancouver. The Vancouver Winter Olympic Games were the third Olympic Games to be hosted in Canada (previously Canada hosted the Montreal 1976 Summer Olympic Games and the Calgary 1988 Winter Olympic Games) with Canada having failed twice to win a single gold medal on home soil - the only host country in Olympic history to do so. In response to Canada's successful bid and to ensure that Canada would achieve its target of first place on the podium at the 2010 Olympic Winter Games and place top three at the 2010 Paralympic Winter Games (Priestner Allinger \& Allinger, 2004), high performance stakeholders established a $\mathrm{C} \$ 117$ million technical program initiative entitled 'Own the Podium 2010' (OTP) (Priestner Allinger \& Allinger, 2004). The following high performance stakeholders met in Calgary: Sport Canada, National/Multi-Sport Organisations, the Canadian Olympic Committee (COC), the Canadian Paralympic Committee (CPC), the Canadian Sport Centres/Institute Network, and WinSport Canada (previously the Canadian Olympic Delivery Authority)

The initiative began in 2004, and was specifically designed to ensure that Canada had its most successful Olympic Games ever by "provid[ing] expertise and leadership to NSOs whose athletes are capable of winning medals at the 2010 Winter Games" (OTP, n.d.b., p. 1). This unprecedented collaborative venture 
resulted in the creation of Canada's first ever agency for high performance sport.

These developments (i.e. Vancouver 2010 Winter Olympic and Paralympic Games and the creation of OTP) have also been paralleled, and largely supported by, a substantial increase in federal government investment in high performance sport in recent years (De Bosscher, Bingham, Shibli, Van Bottenburg, \& De Knop, 2006; Green \& Houlihan, 2005; Grix \& Carmichael, 2012; Thibault \& Harvey, 2013). Over the previous two summer Olympic quadrennials, for example, Canada has witnessed a doubling of federal government investment into Olympic summer sports programs from $C \$ 52,297,871$ during the Beijing quadrennial to $C \$ 117,512,216$ in the lead up to the London 2012 Games (OTP, n.d.a). This increased levels of investment have, however, resulted in increasing involvement of federal government in sport to ensure that taxpayer funding is well spent (Green \& Houlihan, 2005; Thibault \& Harvey, 2013). The implications of this increasing involvement of government in sport generally and Canadian sport specifically has been well documented (Green \& Houlihan, 2005; Grix \& Carmichael, 2012; Macintosh, Bedecki, \& Franks, 1990; Macintosh \& Whitson, 1990; Thibault \& Harvey, 2013).

In light of the ongoing amateur sportrelated discussions surrounding organizational change and reform and the abovementioned major developments within Canadian sport, more research is required to understand how these recent developments - particularly federal government-related developments - have influenced amateur sport organizations in Canada. As Thibault and Harvey (2013) note, "contemporary analysis of government involvement in 'amateur' sport is not only warranted, it is essential given the significant changes that have occurred in Canadian sport" (Thibault \& Harvey, 2013, p. 11). Hence, although previous scholarship has provided valuable contributions to our understanding of the nature and extent of these broader sociopolitical shifts (e.g., modernization and governance), little is still known about the specific consequences of these broader shifts for sport organizations further down the delivery system (for exceptions within the UK context see Adams, 2011; Grix, 2009). Questions that still remain unanswered within the Canadian sport context include, for example, how has Canada's successful bid and subsequent hosting influenced sport organizations in Canada? Similarly, what influence (if any) has the creation of OTP had on sport organizations? As such, the purpose of this investigation is to explore the influence of these recent developments on the policymaking processes of one NSO: Athletics Canada. To this end, we draw upon the discussions surrounding the modernization of sport and the insights generated from a singular case study of Athletics Canada to examine how the organizations' policy- 
making processes have changed over a $10-$ year period (2002-2012).

\section{Modernization and sport}

Many scholars have examined the impact of modernization within sport (cf. Adams, 2011; Green \& Houlihan, 2005, 2006; Grix, 2009; Grix \& Parker, 2011; Houlihan \& Green, 2009; Sam, 2009, 2011) even despite the concept's lack of precision. This is not to suggest that the concept of modernization is meaningless. For Finlayson (2003), "modernisation appears to refer to a large scale sense of change, development and transformation, something different to what has come before" (p. 16). From this perspective, Finlayson (2003, p. 63) described modernization as an 'up' word that implies improvement, progression and change for the better. Houlihan and Green (2009, p. 679) offer the closest articulation to a precise definition by referring to modernization as a particular set themes (e.g., responsiveness, managerialism, responsibilization), principles (e.g., partnership working), technologies (e.g., performance measurements such as benchmarking, public service agreements and auditing), and a narrative that has been used to frame and problematize the current 'state' of public sector management. In this sense, modernization is a persistent aim of government agencies (Sam, 2009) that has come to be viewed as one of the many ways in which governments can shape (i.e. influence) and steer public sector organizations more generally and sport organizations specifically in order to achieve its own objectives.

Houlihan and Green (2009) investigated the causes and consequences of modernization on two Non-Departmental Public Bodies (UK Sport and Sport England) within the United Kingdom. The authors found that modernization was primarily driven by central government, with some evidence of a perceived need for change within the two organizations. The consequences of modernization (i.e. reform) for these governmental agencies were greater decision-making constraints on professional staff, the marginalization of certain sporting interests, and the increasing adoption of business-like principles (e.g., evidence-based decision making and accountability measures). The latter (i.e. the adoption of business-like principles), in particular, had also resulted in a narrowing of organizational objectives - to a point that both organizations were increasingly adopting oversimplified strategic objectives.

Of particular relevance to the present study are the works of Grix and colleagues (Grix, 2009; Grix \& Parker, 2011). Grix (2009) examined the impact of modernization on UK Athletics, the NSO responsible for overseeing track and field athletics in the UK. The author argued that poor international level (i.e. world championships and Olympic/Paralympic Games) performances in the sport could, in part, be attributed to the way in which the NSO was governed. In drawing upon the 
governance debate more broadly and the debates surrounding 'New Managerialism' specifically, Grix (2009) concludes that the values and practices imposed by central government - through its conditional funding agreements - effectively 'straitjacketed' the organization (UK Athletics) in its decision-making capabilities. More specifically, Grix’s (2009) analysis revealed, inter alia, that UK Athletics was characterized by key executive-level personnel turnover and an increasing focus on accountability up towards governmental agencies. According to Grix (2009), UK Athletics has also established a number of auditing technologies; most notably legally binding key performance indicators between UK Athletics and UK Sport. In a follow-up investigation, Grix and Parker (2011) built upon the findings of Grix's UK Athletic case study to provide three explanations for the relative decline of Athletics within the UK. These explanations included: the poor governance of UK Athletics, broader social/societal change, and changes within school sport provision.

In drawing upon the abovementioned policy-related scholarship (namely Green, Grix, and Houlihan), our investigation offers the following threefold contribution to the amateur sport literature. First, our investigation further explores the consequences of modernization within the Canadian sport context. As such, our study contributes an in-depth empirical case study to the small but growing body of literature that has examined the reforms of amateur sport organizations in recent years specifically as they relate to the ongoing modernization process (e.g., Grix, 2009; Houlihan \& Green, 2009). Second, and in building on previous scholarship, this investigation provides a more detailed understanding of how these broader sociopolitical shifts (such as modernization) are influencing the specific decision-making processes of NSOs. Previous scholarship has adopted a broader analytical focus by attempting to examine and understand the nature of these socio-political influences on, for example, governmental agencies (e.g., Houlihan \& Green, 2009; Sam, 2011) or to explain the overall decline of a particular sport (Grix \& Parker, 2011) rather than focusing specifically on the consequences of such reforms on the managerial and decision-making practices of sport organizations further down the delivery chain (i.e. NSOs, clubs etc.). Third, and finally, this article provides an empirical case study analysis into the policy-making processes of one of Canada's most prominent NSOs - Athletics Canada. Consequently we contribute an empirical insight for those interested in more specific discussions surrounding the national and international development of track and field athletics (henceforth athletics) (e.g., Grix, 2009; Grix \& Parker, 2011; Truyens, DeBosscher, Heyndels, \& Westerbeek, 2014). 


\section{Rationale and Research Context}

The empirical data presented herein draws from the Canadian portion of a much larger, international study examining sport policy factors leading to international sporting success (or 'SPLISS') in the sport of Athletics (Truyens et al., 2014). This broader study (Truyens et al., 2014) was a sport-specific follow up investigation to examine the competitiveness of countries in the sport of athletics. More specifically, this follow-up study adapted the SPLISS framework developed by De Bosscher and colleagues (De Bosscher et al., 2006) in order to benchmark (i.e. compare) the development of countries across nine policy areas (or pillars) (see Table 1 for an overview of these policy-areas). A mixed methods approach was employed that involved interviewing key personnel and surveying coaches, athletes and clubs within the sport. The first phase of this broader research project involved the completion of an inventory that examined the 'state of art' of Athletics within Canada. Completion of this inventory required in-depth interviews with key personnel within athletics, particularly Athletics Canada. For the purposes of the present contribution, the researchers adopted a viewpoint similar to that provided by Eisenhardt (1989), who noted that "if a new line of thinking emerges during the research, it makes sense to take advantage... [of it] to provide a new theoretical insight" (p. 539). During the initial research process, a new line of thinking surfaced and a number of reoccurring themes began to emerge from the empirical data in relation to the influence of modernization on the policymaking processes of Athletics Canada.

Athletics Canada is the national governing body for track and field athletics. Originally established in 1884, the not-forprofit organization is one of Canada's oldest NSO (Athletics Canada, n.d.b) and at the time of data collection generated approximately CAD $\$ 6$ million in revenue per annum (e.g., CAD\$6, 019,761 in 2010; Athletics Canada, 2010). Like many NSOs in Canada, Athletics Canada relies heavily upon government funding. Of particular note, Athletics Canada has seen a threefold increase in government funding over the past 10 years; compare for example Beijing (i.e., CAD $\$ 3,151,000)$ and London (i.e., CAD $\$ 10,234,500)$ quadrennials (OTP, n.d.b). Athletics Canada's headquarters is based in Ottawa and employs 15 full-time staff (at the time of data collection) with the mission to "provide leadership, development and competition that ensures world-level performance in athletics" (Athletics Canada, n.d.c). Although centrally coordinated by Athletics Canada, the delivery system of the sport in the country relies heavily upon its ten provincial and two territorial branches. These branches oversee their respective jurisdictions, a majority of grass roots programs, as well as the early development of athletes. This decentralized system of delivery typifies the federated delivery system of Canadian sport (Thibault \& Harvey, 2013). With regard to 
the delivery of elite programs, at the time of data collection Athletics Canada operated four, discipline-specific, national high performance training centers across the country. The centers are located in Victoria (middle distance running), Kamloops (throws), Ottawa/Toronto (sprints and relays), and Calgary (selected technical events).

\section{Methods}

\section{Case Study Approach}

A holistic, single-case study design (Yin, 1994) was adopted to examine the policymaking processes of Athletics Canada. Rossman and Rallis (2003) defined case studies as "in-depth and detailed explorations of single examples (an event, process, organization, group, or individual) that are an instance drawn from a class of similar phenomena" (p. 104). Within case study research, emphasis is placed on developing thick description (Geertz, 1973) of highly complex and contemporary phenomena (typically within their real-life context; Yin, 1994). The utility of this approach lies in its ability to incorporate multiple data sources (Bryman, 2008; Yin, 1994) and is particularly useful in developing theoretical accounts (Eisenhardt, 1989; Einsenhardt \& Graebner, 2007). Thus the (often misunderstood) intention of adopting a case study approach hereafter is to analytically generalize rather than statistically generalize (Flyvbjerg, 2006; Yin, $1994)$ in that this approach provides the opportunity to expand and generate theory rather than to simply enumerate frequencies.

\section{Sampling and Procedure}

As a part of the case study, semistructured interviews were conducted with senior Athletics Canada personnel. Informants were selected primarily based on two criteria: current or former employment in the organization and specific (unparalleled) knowledge of Athletics Canada policy-making processes (Gratton \& Jones, 2010). More specifically, informants were selected due to their knowledge in one (or more) of nine policy areas as identified in the SPLISS conceptual framework (for a detailed overview of these policy areas see De Bosscher et al., 2006). The individuals selected for interview were either part-time or full-time employees involved in the core business or technical operations of the organization. The eight interviewees were between 27 and 55 years of age and generally had 10 or more years of experience in the sport sector.

Interview guides were extracted from the SPLISS Athletics research consortium policy inventory (Truyens et al., 2014). Of the nine conducted interviews (one informant was interviewed twice, with each interview addressing unique policy-making processes), five were carried out face-to-face and took place at Athletics Canada's head office in Ottawa, Ontario and a high performance training camp in Phoenix, Arizona and four were conducted using the online communication program Skype. All 
interviews were conducted by the first author between December 2010 and March 2011, ranged from 38 and 150 minutes in length, and were digitally recorded and transcribed verbatim. These transcripts produced 410 double-spaced pages of data for further analysis.

\section{Understanding the Modernization of Athletics Canada's Policy-Making Processes}

The work of Green and Houlihan (2005) was drawn upon as a baseline comparison to examine how Athletics Canada's policy-making processes had changed over time (i.e. between 2002-2012). In particular, Green and Houlihan's (2005) study provided a detailed examination of internal policy developments and major issues faced by Athletics Canada at the turn of the century (for further insight see Green \& Houlihan, 2005, pp. 110-121). In addition, Green and Houlihan (2005) developed a conceptual framework that considered four areas of elite sport policy: facilities; full-time athletes; coaching, sport science, and sport medicine; and competition opportunities. Green and Houlihan then applied this framework to compare the development of several elite sport organizations and systems (see Green \& Houlihan, 2005; Houlihan \& Green, 2008). For purposes of our present analysis, the work of Green and Houlihan (2005) provided a means to examine the development of Athletics Canada policymaking processes and allowed for a comparison of the substance and salience of prior policies to those established after the inception of OTP. More practically, however, Green and Houlihan's (2005) work on Athletics Canada also provided a useful framework by which to reduce the large amount of data collected as a part of the original SPLISS Athletics study. See Table 1 for an overview of Green and Houlihan (2005) and the SPLISS model (De Bosscher et al., 2006).

\section{Coding}

The primary author undertook a process of independent open coding (Patton, 2002), specifically looking for any policy areas mentioned within Green and Houlihan's (2005) Athletics Canada case study. As a result of this process, a total of 24 specific policy areas were identified (see Table 2). These 24 policy areas were translated into codes and deductively applied to the analysis of transcripts. As to not limit analysis, the transcripts were also analyzed inductively, leaving open the opportunity for identifying new and emerging codes (i.e., policy areas). Allowing for the emergence of such codes was necessary given that some policy areas were either omitted by Green and Houlihan (2005) (e.g., those regarding the school system and talent identification) or not present at the time the initial study (e.g., those regarding the Long Term Athlete Development Model (LTAD) or National Training Centres). As a result of this process, a total of 41 policy areas/codes 
were identified. It was from these policy areas/first order codes that second order codes were derived. The second order codes were then collapsed into three broad, interrelated themes: (i) The development and prioritization of OTP-funded policy-making processes (ii), the development and prioritization of evidence-based policies and programs, and (iii) the further straining of inter-organizational relationships.

\section{Results}

\section{(i) Development and Prioritization of} OTP-Funded Policies and Programs

Following the creation of OTP in 2004, Athletics Canada has developed and prioritized a number of OTP-funded policies and programs. In particular, the organization has utilized OTP funds over the past decade to develop and enhance athlete and coach development, as well as sport science and medicine programs. In an effort to enhance athlete development, for example, Athletics Canada established the Olympic Development Program (ODP) in 2011. The program was created in response to what many respondents described as a set of historically inadequate talent identification and development procedures. As part of the program, and at the time of data collection, Athletics Canada provided support to three tiers of athletes: Tier II athletes, those that achieved a minimum (internally set) performance standard, received both formal recognition and limited support (e.g., yearly planning and competition scheduling); Tier I athletes, those that achieved a comparatively greater performance standard, received increased support (e.g., partial funding, and access to training camps); and 2016 group athletes, those that ranked top eight in the world in a particular sport, received a full range of support (e.g., financing for both the athlete and the coach to attend training camps and competitions).

As Athletics Canada directed funding to high performance athletes, it simultaneously redirected funding from athletes elsewhere along the development pathway. Chiefly affected in this regard was Run Jump Throw, the organization's grassroots, participation-based program:

When we started with Run Jump Throw five or six years ago, the funding model was similar, but not quite as targeted, and there was more money available from Sport Canada for development. At one time, Run Jump Throw had an operating budget of over $\$ 200,000$, because there was a large licensing agreement that was struck with the Hershey Company, for over three or four years, and we were receiving over $\$ 100,000 /$ year from Sport Canada. And in the last couple of years, Sport Canada dollars have been decreased significantly, to about half. Also, the deal with Hershey's was re-negotiated and there was less money there... And right now, if we were to say, 'Hey, let's start our grassroots development programs,' it'd be a lot more difficult than it was five years ago because the 
funding model has changed.

(Respondent Four, 02/25/11)

Addressing the development-related issues that resulted from change to the aforementioned funding model was Respondent Eight:

I hear about it every year, from angry coaches, athletes, and parents, who say, 'How is it that my son or daughter, as an athlete, has to pay to represent Canada?' I wish I had a better answer for them. We just don't have the resources to be able to do it, and we're in a system where those resources are attached to strings. We have a bunch of money that we want to give you, but it can only go into this pot. You can't take from us to help all those people.' And I understand targeting, and focus, but I just wish that there was more of an understanding of the long term development of an athlete.... I mean, there's a long road before they get to be top eight in the world, and we need to find a way to fund that. This is really important, what Own the Podium is doing, but we need to find a way to help them along that path before they get there. We have this short term need to win medals at the next [event], and we forget to have a longer perspective for 2016 and $2020(02 / 04 / 11)$

As the above quotation intimates, the consequences resulting from the adopted funding strategy extended to the organization's ability to support athletes in a manner consistent with the Sport Canada- mandated sport-specific LTAD plan. Athletics Canada, as such, became embroiled in a strategic dilemma in whether to enhance development opportunities for high performance athletes in accordance with the mandate of OTP on the one hand, or enhance development opportunities for all in accordance with the mandate more consistent with Sport Canada's LTAD on the other. Over the period of this study, the organization's focus lay in the former and not the latter.

The development and prioritization of OTP-funded policies and programs was also evident in Athletics Canada's development of high performance coaches. This development can be traced back to the creation of a coaching development position within Athletics Canada in 2006. Prior to the creation of this position, Athletics Canada had not assigned any individual the responsibility of overseeing the development and education of relevant coaches. The appointed manager, responding to both the potential for melioration and a set of sport-wide recommendations provided by the Canadian National Coaching Certification Council, subsequently restructured Athletics Canada's coaching development system. The restructured system, simply titled the New Athletics Canada National Coaching Certification Program (NCCP), differed from its predecessor in several regards, most apparently in relation to curriculum design and certification. The previous curriculum design comprised of five levels, 
each with three components (theory, technical, and practical), whereas the new system consisted of three streams (representing model coaching environments; instruction, community, competition) focused on a single component - competency. Similarly, certification was once dispensed in accordance with the completion of a particular curriculum level. The new program reflects competency in a specific coaching stream and context (e.g., beginner instruction through to high performance). These and other such changes indicate a marked increase in the formalization of Athletics Canada's coaching development system.

The formalized system, despite accounting for an entire spectrum of coaches, facilitated a narrowing of the organization's orientation and domain. This was evidenced through the development and prioritization of a refined high performance coaching development program (reflective of one of six new certification contexts). The program, targeted in scope and available only to a select few participants, was developed in such a manner as to align with the agenda of OTP, and, as a consequence, better ensure the continued receipt of financial support. The distribution of such support by Athletics Canada, was not, however, inclusive; instead, it reinforced the increasingly salient high performance agenda. In discussing the organization's provision of support to various streams and contexts/programs, Respondent Four stated:

Athletics Canada oversees... all of the coach education programs in the country, from Run Jump Throw (the sole program for both the instruction and community streams), which is a grassroots program, right through to high performance. The actual delivery of the Run Jump Throw and grassroots programs is the responsibility of the [provincial] branches. We take over as the primary provider of competition development and higher, so developing high performance and elite coaching education.... At Level Three, the new competition development (the introductory program in the competition stream), we don't really support them other than by providing opportunities for education. It's really the branches that fund them. They pay for it so there's not necessarily a lot of support there for them... We're working on determining our policy of how competition development advanced coaches (the mediate program in the competition stream) will be supported... And then at Level Five, the OTP level (the high performance program in the competition stream), we develop an individual learning plan and apply for funding, and when we're successful, those opportunities are fully funded through Athletics Canada/OTP. (02/25/11) 
The quotation indirectly highlights the disparate levels of support that Athletics Canada had provided to its various coaching development programs. The sole program for both the instruction and community streams, despite a sound infrastructure (e.g., set of policies), operated almost exclusively outside the purview of the organization. In contrast, the introductory and mediate programs in the competition stream lacked both policies and financing. The high performance program in the competition stream, finally, received both significant administrative and financial support. Athletics Canada, then, has, as it did with athlete support, prioritized high performance coaches at the expense of their sub-elite equivalents and grassroots participants.

The abovementioned issues, pertaining to domain (i.e., areas of service provision), were exacerbated by the organization's increased development and prioritization of sport science and medicine programs. The sport science program, for example, was enhanced through equipment (e.g., shoe, bodysuit) design interventions, the accumulation of "competitive intelligence" (i.e., information pertaining to other countries' developmental and competitive practices), and the engagement in, and incorporation of, biomechanical research. Responsible, in part, for the communications of conducted research were clinicians appointed to the organization's expanded sport medicine program. This program differed from its earlier counterparts in that it featured an integrated support team (consisting of various clinicians), employed preventative (rather than reactive) care and science, and introduced a new set of performance-related tests and analyses.

These measures, as well as those associated with the sport science program, were considered as integral not only to the organization's pursuit of sporting excellence, but also to retaining the financial and administrative support of OTP. Affirming the organization's increased prioritization of sport science and medicine programs, and speaking to the related developmental role of OTP, was Respondent One:

We expect to see a sport science and sport medicine program as part of application, and it better be something that's real, something that you're using, something that's evolving, and something that has impact. Would we have done it without [the support of OTP]? Yeah. But would we have been as compelled, or as organized, or as well resourced? No. So this really helped. Own the Podium is very good. They [OTP] push us a bit, but they pull us along, and they accompany us at the same time. They're really, really good partners. $(02 / 26 / 11)$ The organization's sport science and medicine programs, as such, reinforced the pursuit of a high performance mandate. It is worth noting as well that although these programs resulted in positive consequences 
for less elite athlete groups, these groups were seldom the intended beneficiaries. As Respondent One, in addressing a question of OTP funding criteria and finance disbursement, remarked:

The criteria are, 'Will they impact podium performance at a major games?' That's the starting and ending point, quite frankly... Well, there always is an element of, 'How will this impact future performances? Does this have a broad enough application that it can be brought to the sport as a whole, and not just the elite level in this particular timeframe?' The work we're doing right now in the relay exchange area is something that will have a broad application to all of our relay teams; whether they're a youth or junior team, it would refine our relay protocols to a smaller or greater degree... Some of them would parlay into greater system change, better system thinking, but quite a bit of it would be individual athlete specific. $(02 / 26 / 11)$

The assumption being made by the respondent here, and the assumption of the organization's development and prioritization of high performance-related policy-making processes more generally, is that the development of elite athlete and coach programs (in line with the mandate of OTP) will, in turn, have knock-on or 'spillover' effects on those further down the delivery system.

\section{(ii) Development and Prioritization of} Evidence-Based Policies and Programs

As Athletics Canada became further aligned with OTP's high performance objectives, it has also began to develop and prioritize a set of related, evidence-based policy-making processes. Developments in relation to Athletics Canada specifically involved the increased incorporation and employment of objective performance measures. The use of such measures was integral to the organization not only in projecting a form of accountability and responsiveness to the leading national sport agencies (e.g., Sport Canada, Canadian Olympic Committee, and Own the Podium), but also in determining the manners and streams in which the agencies' financing would be utilized. Addressing the interrelationship between the employment of objective measures (i.e., "evidence") and the organization's financing of particular high performance sport streams was Respondent Five:

Every decision we're taking, when we're putting the blocks of our strategic plan in the high performance area, we need to have evidence.... And we had enough evidence in terms of long distance running and race walking to say that we just don't have the athletes.... Again, it all goes back to, 'We need to have evidence to decide what to do. We cannot just go on impression.' $(02 / 04 / 11)$

For Athletics Canada, then, decisions pertaining to high performance sport 
became increasingly tied to measurable results.

Nowhere was this increasingly evidencebased approach to decision-making more apparent than in an organizational policy that pertained to the country's Athlete Assistance Program (AAP). Developed and managed by Sport Canada, the program supports select athletes through the provision of living, training allowances, and academic scholarships (Athletics Canada, n.d.a). Athletics Canada's role in this program is the identification and selection of eligible, sport-specific beneficiaries (colloquially referred to as 'card recipients') who can then be recommended to Sport Canada. It is in this regard that the organization has increased its incorporation and employment of objective performance measures. Describing in detail the manner in which the organization's AAP policy has been revised was Respondent Eight:

... The way the criteria (for selecting beneficiaries) were done and written was not clear. It was not objective enough in the minds of the people who were out there... So at that time (2005), I gathered as much information as I could from people, and I created a point system which ranked athletes.... There were different categories, and a part of it was training, coaching environment, but then there was also how you did at nationals (national events), how you did at international events, what your top three performances averaged out to, and those types of things. And it worked in terms of being defendable, defensible, objective, and clear to people $(02 / 04 / 11)$ Although Athletics Canada's AAP policy was subsequently revised to what one respondent referred to as "something that's a little more subjective" (Respondent Eight, 02/04/11), it retained a far more stringent set of criteria than any of its pre-2002 equivalents. The evidence-based policy thus reinforced the newly adopted organizational value of objective and evidence-based decision-making.

The impact of the revised policy's formality was also particularly evident in the organization's talent identification and athlete development procedures. Prior to the policy's revision, these procedures were generally lacking in stringent guidelines and criteria for identifying and segmenting elite athletes. The same, however, could not be said for these procedures following the policy's revision. Retracing the development of these procedures and the related impact of the revised AAP policy (i.e., "criteria," "carding streams") was Respondent Two: What I believe is that we worked very hard in creating our high performance structure, and setting out all the strategies, and criteria, and very specific goals of top eight at podium, and that the development part was not matching it; it was just something out there, with no rhyme or reason, that needed to be organized more and aligned with everything that we were doing.... We 
had no direction before. And we had no criteria proof that we had talent... Sometimes we got suckered into being convinced that we had talent. Now, because everything is aligned with the carding streams, and everything is directed through top eight, we can actually confidently say, 'This is some serious talent. This talent is staying on stream. It's showing all the signs, and we know we can put some effort and money in to that.' $(02 / 26 / 11)$

In aligning talent identification and athlete development procedures with the revised AAP policy, Athletics Canada was ultimately able to set in place the framework for the previously described Olympic Development Program (ODP). It was also suggested, by at least one respondent, that this alignment could ease the process by which the organization narrowed its domain (from one that emphasized high performance sport in general to one that emphasized a select few high performance sport sub-disciplines, e.g., sprint, middle distance, and relay track events). The development of high performance-related, evidence-based policymaking processes thus included the formalization of a beneficiary plan, the creation of the ODP, and may yet still result in the narrowing of focus to support select high performance sport disciplines.

Athletics Canada's development and prioritization of evidence-based, high performance-related policy-making processes was apparent not only in the above examples, but also in the organization's decreased support of its Run Jump Throw program. The program was originally assembled some 20 years ago in an effort to enhance the physical fitness, health, and maturation of Canadian children six to twelve years of age. Despite its longevity and merits, the program as historically lacked a catalogue of objective performance measures (e.g., rates of continued participation, club memberships resulting from program participation). It was as a result of this decreased support that the program saw reductions in both funding and responsible personnel, with its implementation increasingly outsourced to provincial and territorial branches. Short of any intervention, the established future trajectory of the program is unlikely to experience any significant alteration. The fate of Run Jump Throw, as such, can therefore be viewed as emblematic of Athletics Canada's increased development and prioritization of high performancerelated, evidence-based policy-making processes.

\section{(iii) Strained Inter-organizational Relationships}

As illustrated by the above example of continued outsourcing of the Run Jump Throw program, the narrowing of Athletics Canada strategic focus has also had consequences that extended beyond the operations of the organization. This was particularly evident through Athletic Canada's attempts to create a strategic plan that incorporated provincial and territorial 
branches. Also affected by this plan were local clubs and Canadian interuniversity athletic programs. For Athletics Canada, the advancement of its high performance agenda necessitated the introduction of a strategic plan that incorporated both provincial and territorial branches. It can be argued that the particular grounds for such a plan stemmed from a disconnect in organizational domains: whereas the national organization increasingly valued those programs and activities that supported high performance sport, some provincial and territorial branches valued those programs and activities that encouraged general participation. The concern for Athletics Canada, then, was how to align all provincial and territorial branches with a high performance feeder system. According to one respondent, Athletics Canada initially attempted to achieve alignment through the use of individual, province-byprovince/territory-by-territory memorandums of understanding. When these attempts failed, the organization sought to develop, with the assistance of individual branches, a singular, cohesive plan. One respondent's optimism relating to the prospects of implementing this plan were, however, rather limited:

It's going to be challenging. It's going to be challenging because... (searching for the words). The reality is that the members (provincial/territorial branches) don't have the capacity to work on these kinds of things. It's always the same people doing the same kind of things, so sometimes they cannot [commit] time to that. And secondly, they are so - They're trying to survive, in some cases, and so for them to do these kind of things is not a priority, because they have other things to do rather than trying to align. And also, some have a tough time understanding what we're doing at the high performance level. (Respondent Five, 02/04/11)

Impediments relating to the implementation of the plan were therefore numerous; included among these were a disconnected set of organizational domains and orientations, as well as a limited amount of organizational capacity. The variance in organizational values ultimately undermined any potential for compromise, with a select few respondents suggesting that this had led to an increasingly strained relationship between the involved parties.

Local clubs, much like provincial and territorial branches, were also expected to be aligned with a high performance feeder system. In some respects, Athletics Canada achieved this end. Talent identification efforts at the level of local clubs were increased, and identified athletes were regularly moved into one of several national training centres. According to some respondents, the interventions on the part of Athletics Canada to move athletes to nationally recognized training centres, were not, however, always well received by local club managers or coaches. For some coaches, intervention primarily resulted in a 
diminished sense of autonomy (local club managers and coaches no longer held the exclusive responsibility of identifying and developing elite junior athletes, but rather had to share this responsibility with Athletics Canada and national training centre personnel). This matter was further complicated as Athletics Canada had not endeavoured to garner the explicit cooperation of club personnel. The cumulative effect of these actions was, according to Respondent 2, the creation of a distrusting relationship, one that required the attention of Athletics Canada:

Early on, at the age of 17, the biggest role for Athletics Canada is to create relationships with those clubs and coaches - to create a trusting communication relationship - and to [let them know] that, 'I am not here to steal your athlete. I'm recognizing that you've done something very positive, and let me help you to continue to ensure that that athlete stays on that high performance stream'.... The one thing that we're struggling with is getting those clubs to realize that they have maxed out on what they can offer an athlete, and when it is time to consider either creating a relationship with a national association, or a national event group, or moving an athlete to a [national training] centre, and that's a piece that Canada seems to not like. They don't really want to go there. And the only way I think that we can convince people is that we start showing some success, in the centres. And because the centre concept is so new it's going to take time. $(02 / 26 / 11)$ For this Athletics Canada employee, then, NSO intervention to move athletes to nationally recognized training centres in the operation of local clubs, despite any resultant benefits (e.g., improved athlete training opportunities, decreased club expenditures), led to strained interorganizational relationships.

The final group of organizations expected to be aligned with a high performance feeder system was to come from Canadian Interuniversity Sport. The alignment of interuniversity sport programs was particularly integral to Athletics Canada for two primary reasons: the provision of proximate and meaningful training opportunities, and the availability of support (e.g., educational and expert resources) for athlete retention efforts. Athletics Canada, however, experienced difficulties in their relationships with these programs.

Addressing these difficulties, as well as the need for related amelioration, was, again, Respondent Two:

The relationship, and I don't understand why, has been strained. And I think primarily just because the universities have one major focus, on the indoor season, and we have our focus, on the outdoor season. I don't understand. There's a whole bunch of history. But I see - for recruiting, retention, and talent development - that has to become a stronger relationship, 
because they are taking the athletes in the first half of my ODP program. So it's a weakness right now that I'm desperately trying to sort out. $(02 / 26 / 11)$

The response from Canadian interuniversity athletic programs, to Athletics Canada's intervention, was therefore similar to those that came from provincial/territorial branches and local clubs. In each example, the strategic plan presented a novel set of organizational values, challenged existent modes of operation, and threatened to reduce levels of autonomy. Given such conditions, it should not be surprising that the advancement of a high performance agenda resulted in several strained interorganizational relationships.

\section{Discussion and Conclusion}

This article examined the consequences of modernization on the policy-making processes of a singular NSO: Athletics Canada. In drawing upon the works of Green and Houlihan (2005) as a baseline comparison, this article provided a descriptive case study analysis of how the policy-making processes of an NSO have changed over a 10-year period (2002-2012). The above analysis brings to the forefront a number of key points of discussion that can be can be drawn out from the research findings. First and foremost, consistent with previous modernization-related works (Adams, 2011; Green \& Houlihan, 2005, 2006; Grix, 2009; Grix \& Parker, 2011; Houlihan \& Green, 2009), it is evident that many of the developments that have occurred within Athletics Canada over the past decade have been governmental-driven, high performance focused, and increasingly evidence-based. Furthermore, the programs and policies that have seen the most development (i.e. have been prioritized) by Athletics Canada, have primarily been those that are heavily supported and facilitated by OTP. In particular, programs that have seen most support in recent years have been those surrounding high performance athlete support (e.g., sport science and medicine programs) and athlete and development (e.g., the ODP and AAP carding criteria).

It also apparent, from our data at least, that the nurturing and development of high performance related and OTP-driven programs and policies has often come at the expense or at least reduced support of other wider-social and participation based programs. This finding was emblematic in the above discussions surrounding the decreased support of the Run Jump Throw program since the mid-2000s. More broadly, then, our empirical case study of Athletics Canada lends support for Green and Houlihan's (2005) viewpoint that mass and elite objectives are fundamentally not compatible. As Green and Houlihan (2005) conclude in their seminal study of sport policy change, "it is hard to avoid the conclusion that elite sport development and achievement on the one hand and mass participation and club development on the other are deeply incompatible functions within the policy frameworks current in 
Australia, Canada and the UK" (p. 189). Our case study supports Green and Houlihan's (2005) notion of incompatibility in that we revealed a number of specific examples of decision-making (e.g., the ODP, RJT, and AAP carding) whereby Athletics Canada has had to prioritize the pursuit of high performance sport at the expense of participation-based objectives. Furthermore, these incompatibilities were also evident within the requirements imposed by Canada's two lead governing agencies themselves. To provide an example, there is a clear dilemma for Athletics Canada to achieve the short-term, medal driven targets set by Own the Podium on the one hand, versus Sport Canada's requirement to adopt and implement the long-term, holistic LTAD model approach on the other.

Perhaps one of the more pertinent findings of our case study analysis of Athletics Canada, and closely linked to the above discussion regarding the development of select policies and programs, is further evidence to support the notion that the decision-making capabilities of the organization are heavily constrained by its governmental agency funding dependencies (namely Own the Podium and Sport Canada). These funding dependencies, in turn, effectively ensure that allocation of public funding comes with 'strings attached' to ensure that taxpayers funding is well spent (Green \& Houlihan, 2005). As Grix (2009) notes in his analysis of UK Athletics (UKA), "the hierarchical chain of power from government down to NGBs [NSOs] has effectively strait-jacketed UKA into delivering a narrow, Olympic-driven sports policy to meet government set targets, which leaves little time and resources to address the factors behind the sports' general decline" (p. 46). Similarly, our analysis of Athletics Canada suggests that the organization is now operating under heavy constraint - most apparently by Own the Podium - to focus on and deliver short, term, Olympic-medal success. As such, many of the decisions by Athletics Canada professional staff since the turn of the century can be viewed as attempts to ensure compliance with its funding partners and ultimately to ensure the organizations' survival. In brief, Athletics Canada's decision-making capabilities are very much constrained within the 'rules of the game' currently dictated by federal government (via Own the Podium and Sport Canada) (Green \& Houlihan, 2006).

What can also be drawn from the above review are the apparent similarities of the characteristics of reform evident within Athletics Canada compared to those experienced by UK Athletics (as reported by Grix, 2009). It is apparent from our analysis that both organizations have undergone strikingly similar reforms since the turn of the century. To provide examples of a few instances:

- Both organizations (UK Athletics and Athletics Canada) have been the subject of organizational 
reform and key personnel

turnover;

- Both organizations have undergone a narrowing of their strategic focus - specifically to Olympic-driven medal success;

- Due to funding and resource constraints, both organizations are increasingly adopting a more strategic approach in terms of athletes and sub-discipline investment;

- Both organizations exhibit a shift in accountability away from its members and clubs (i.e. grassroots stakeholders) and upwards towards governmental agencies (via Own the Podium and Sport Canada);

- Both organizations have increasingly adopted an evidencebased (i.e. 'New Managerial') approach to their policy/decisionmaking processes.

One notable difference between our analysis of Athletics Canada and Grix's (2009) analysis within the UK equivalent NSO, however, is that UKA and English Athletics specifically have been able to set key performance indicators between itself and its regional branches. As Grix (2009) notes, "English Athletics, for example sets some 130 KPIs to be met by its regional branches" (p. 40). In contrast, Athletics Canada has been unable to impose such targets on its member branches to date. This can in part, be explained by Canada's multi-level, federalist sport system (Thibault
\& Harvey, 2013) and the relative independence of the provincial/territorial branches compared to the UK.

The latter part of our review (i.e. discussions surrounding inter-organizational strain) bring to the forefront what Sam (2009) described as the 'wicked nature' of sport policy, particularly as they relate to the modernization of NSOs. Specifically, Athletics Canada's inability to formulate and agree-upon coherent development pathway plans with its provincial/territorial branches, the growing lack of trust between Athletics Canada and clubs, and the strained relationship between Athletics Canada and the CIS can all collectively be viewed as the 'unintended consequences' (i.e. product) of an NSO seeking to develop partnerships under the assumptions of a managerialist logic. For Sam (2009), "given the resounding justification for the modernizing agenda is for NSOs to be better attuned to the needs and demands of stakeholders, it remains to be seen whether more modern and commercialized practices will indeed raise their capacities to do so" (p. 510). From the data collected, it seems apparent that the modernization of Athletics Canada is shifting the organizations' focus up to governmental agencies and away from the needs and demands of its stakeholders further down the delivery chain. The concern here, is the production of a 'democratic deficit' (Houlihan \& Green, 2009) whereby decision-making in relation to the development of the sport is made 
top-down rather than bottom-up and often at the expense or marginalization of certain stakeholders and groups.

In turning to the contributions of our case study analysis to the literature, this investigation explored further the consequences of modernization within the Canadian sport context. More specifically, our analysis built upon the works of Green and Houlihan (2005) to examine the consequences of modernization over a ten year period (2002-2012), and in doing so, contributes an in-depth empirical case study to the small but growing body of literature that has examined the reforms of amateur sport organizations in recent years (e.g., Adams, 2011; Grix, 2009; Houlihan \& Green, 2009; Sam, 2009, 2011). In relation to limitations and directions for future research, it is acknowledged that this investigation did not originally set out to study the consequences of NSO reform. Future studies should therefore be constructed specifically to do so. Furthermore, the analysis was methodologically limited in that it only considered one organization. Future research could therefore expand the empirical site to include more NSOs (although valuable work has already been done here, cf Kikulis et al., 1992; Green \& Houlihan, 2005), and to examine the influence of modernization on sports organizations further down the delivery system (i.e., provincial/ territorial branches and clubs). Finally, this research highlighted the continued and notable role that OTP is playing in terms of modernizing NSOs within the Canadian sporting context. It is evident from our case study of Athletics Canada that OTP is now a key driving force for the modernisation agenda evident within Canada and more needs to be done to understand how this nascent organization is influencing the Canadian sporting landscape. 


\section{References}

Adams, A. (2011). Between modernization and mutual aid: the changing perceptions of voluntary sports clubs in England. International Journal of Sport Policy and Politics, 3, 23-43. doi:10/1080/19406940.2010.54463

Athletics Canada (n.d.a). Athlete Assistance Program (carding). Retrieved January 14, 2013, from http://www.athletics.ca/page.asp?id $=155$

Athletics Canada (n.d.b). History. Retrieved November 9, 2012, from http://www.athletics.ca/page.asp?id $=44$

Athletics Canada (n.d.c). Who we are. Retrieved November 9, 2012, from http://www.athletics.ca/page.asp?id $=9$

Bryman, A. (2008). Social Research Methods. ( $2^{\text {nd }}$ Edn.). Oxford: Oxford University Press

De Bosscher, V., De Knop, P., Van Bottenburg, M., \& Shibli, S. (2006). A conceptual framework for analysing sports policy factors leading to international sporting success. European Sport Management Quarterly, 6, 185-215. doi:10.1080/16184740600955087

Eisenhardt, K. M. (1989). Building theories from case study research. Academy of Management Review, 14, 532-550. doi:10.5465/AMR.1989.4308385

Eisenhardt, K. M., \& Graebner, M. E. (2007). Theory building from cases:
Opportunities and challenges. Academy of Management Journal, 50, 2532.

doi:D10.5465/AMJ.2007.24160888

Finlayson, A. (2003).The meaning of modernization. Soundings, 23, 62-83.

Flyvbjerg, B. (2006). Five misunderstandings about case-study research. Qualitative Inquiry, 12(2), 219-245. doi: $10.1177 / 1077800405284363$

Geertz, C. (1973). Thick description: Toward an interpretive theory of culture. In C. Geertz (Ed.), The interpretation of cultures (pp. 3-30). New York: Basic Books.

Goodwin, M., \& Grix, J. (2011). Bringing structures back in: the 'governance narrative', the 'decentred approach' and 'asymmetrical network governance' in the education and sport policy communities. Public Administration, 89(2), 537-556.

Gratton, C., \& Jones, I. (2010). Research methods for sport studies (2nd Edn.). London: Routledge.

Green, M. (2004). Changing policy priorities for sport in England: the emergence of elite sport development as a key policy concern. Leisure Studies, 23(4), 365-385.

Green, M. (2007). Policy transfer, lesson drawing and perspective on elite sport development systems. International Journal of Sport Marketing and Management, 2(4), 426-441. doi:10.1504/IJSMM.2007.013715 
Green, M., \& Houlihan, B. (2005). Elite sport development: Policy learning and political priorities. London: Routledge.

Grix, J. (2010). The 'governance debate' and the study of sport policy. International Journal of Sport Policy, 2(2), 159-171.

Grix, J., \& Carmichael, F. (2012). Why do governments invest in elite sport? A polemic. International Journal of Sport Policy and Politics, 4, 73-90.

Grix, J., \& Parker, A. (2011). Towards an explanation for the decline of athletics in the UK: A case study of male distance running. Sport in Society, 14(5), 612-628.

Grix, J., \& Phillpots, L. (2011). Revisiting the 'Governance Narrative' 'Asymmetrical Network Governance' and the Deviant Case of the Sports Policy Sector. Public policy and administration, 26(1), 3-19.

Houlihan, B., \& Green, M (Eds) (2008). Comparative elite sport development: systems, structures and public policy. Oxford: Elsevier/ButterworthHeinemann.

Houlihan, B., \& Green, M. (2009). Modernization and sport: The reform of Sport England and UK Sport. Public Administration, 87, 678-698. doi:10.1111/j.14679299.2008.01733.x

Hoye, R., \& Cuskelly, G. (2007). Sport governance. (Eds.). Oxford: Elsevier

Kikulis, L. M., Slack, T., \& Hinings, B. (1992). Institutionally specific design archetypes: A framework for understanding change in national sport organizations. International Review for the Sociology of Sport, 27, 343368.

doi:10.1177/101269029202700405

Macintosh, D., Bedecki, T., \& Franks, C. E. S. (1987). Sport and politics in Canada: Federal government involvement since 1961. Kingston, ON: McGill-Queen's University Press.

Macintosh, D., \& Whitson, D. (1990). The game planners: Transforming Canada's sport system. Montreal, QC: McGillQueen's University Press.

O'Brien, D., \& Slack, T. (2003). An analysis of change in an organizational field: The professionalization of English rugby union. Journal of Sport Management, 17, 417-448.

O'Brien, D., \& Slack, T. (2004). The emergence of a professional logic in English rugby union: The role of isomorphic and diffusion processes. Journal of Sport Management, 18, 13-39.

Own the Podium. (n.d.a). About OTP.

Retrieved June 10, 2012, from http://ownthepodium.org/About/

Own the Podium. (n.d.b). Summer Historical Comparison. Retrieved June 10, 2012, from

http://ownthepodium.org/Funding/ Summer-Historical-Comparison.aspx Patton, M. Q. (2002). Qualitative research and evaluation methods. Thousand Oaks, CA: Sage.

Phillpots, L., Grix, J., \& Quarmby, T. (2011). Centralized grassroots sport 
policy and 'new governance': A case study of County Sports Partnerships in the UK-unpacking the paradox. International Review for the Sociology of Sport, 46(3), 265-281.

Priestner Allinger, C., \& Allinger, T. (2004).

Own the Podium: 2010 final report.

Retrieved from:

http://www.sportmatters.ca/files/Gr oups/SMG\%20Resources/Sport $\% 20$ and $\% 20 \mathrm{PA} \% 20$ Policy/otp_report__final_-_e.pdf

Rhodes, R. A. W. (1996). The new governance: governing without government. Political studies, 44(4), 652-667.

Rossman, G. B., \& Rallis, S. F. (2003). Learning in the field: An introduction to qualitative research (2nd ed.). Thousand Oaks, CA: Sage.

Sam, M. P. (2009). The Public Management of Sport. Public Management Review, 11(4), 499-514.

Sam, M. P. (2011). Building legitimacy at Sport Canada: pitfalls of public value creation. International Review of Administrative Sciences, 77(4), 757-778.

Shilbury, D., \& Ferkins, L. (2011).

Professionalisation, sport governance and strategic capability. Managing Leisure, 16(2), 108-127.

Slack, T. (Ed) (2004). The commercialisation of sport. London: Routledge.

Slack, T., Berrett, T., \& Mistry, K. (1994). Rational planning systems as a source of organizational conflict. International Review for the Sociology of Sport, 29, 317-
328.

doi:10.1177/101269029402900306

Slack, T., \& Hinings, B. (1994). Institutional pressures and isomorphic change: An empirical test. Organization Studies, 15, 803-827. doi:10.1177/017084069401500602

Thibault, L., \& Harvey, J. (Eds.). (2013). Sport policy in Canada. Ottawa: Ottawa University Press.

Thibault, L., Slack, T., \& Hinings, B. (1991). Professionalism, structures and systems: The impact of professional staff on voluntary sport organizations. International Review for the Sociology of Sport, 26, 83-98. doi:10.1177/101269029102600202

Truyens, J., De Bosscher, V., \& Heyndels, B., \& Westerbeek, H. (2014). A resource-based perspective on countries' competitive advantage in elite athletics, 6(3), 459-489. doi: 10.1080/19406940.2013.839954

Yin, R. (1994). Case study research: Design and methods (2nd ed.). Thousand Oaks, CA: Sage.

Washington, M., \& Patterson, K. (2011). Hostile takeover or joint venture? Connections between institutional theory and sport management research, Sport Management Review, 14, 1-12. doi:10.1016/j.smr.2010.06.003 


\section{Table 1}

\section{Tables}

Comparative Elite Sport Policy Model Factors

\begin{tabular}{|c|c|}
\hline Green \& Houlihan (2005) & De Bosscher et al. (2006) \\
\hline & 1. Financial Support \\
\hline \multirow[t]{2}{*}{ 1. Development of Elite Facilities } & 2. Policy Development \\
\hline & 3. Participation \\
\hline \multirow[t]{2}{*}{ 2. Emergence of 'Full-Time' Athletes } & 4. Talent ID and Development \\
\hline & 5. Athletic \& Post-Career Support \\
\hline 3. Developments in Coaching, Sport Science \& & 6. Training Facilities \\
\hline Medicine & $\begin{array}{l}\text { 7. Coaching Provision \& Coach Development } \\
\text { 8. (Inter)national Competition }\end{array}$ \\
\hline 4. Competition Opportunities for Elite Athletes & 9. Scientific Research \\
\hline
\end{tabular}

Table 2

Extracted Athletics Canada Themes from Green \& Houlihan (2005)

\begin{tabular}{|c|c|c|c|}
\hline $\begin{array}{l}\text { Development of Elite Level } \\
\text { Facilities }\end{array}$ & $\begin{array}{l}\text { Emergence of full time' } \\
\text { Atbletes }\end{array}$ & $\begin{array}{l}\text { Developments in Coaching, } \\
\text { Sport Science \& Medicine }\end{array}$ & $\begin{array}{l}\text { Competition Opportunities } \\
\text { for Elite Athletes }\end{array}$ \\
\hline a. No National & e. Athlete going to US & j. Few 'Full-Time' & r. Variance in \\
\hline Strategic Facility Plan & $\begin{array}{l}+ \text { over reliance on } \\
\text { AAP }\end{array}$ & Coaches Employed & $\begin{array}{l}\text { Competition at all } \\
\text { levels }\end{array}$ \\
\hline $\begin{array}{l}\text { b. Public Perception of } \\
\text { Athletics }\end{array}$ & $\begin{array}{l}\text { f. Non-Eligibility of } \\
\text { AAP for NCAA } \\
\text { Canadians }\end{array}$ & $\begin{array}{l}\text { k. Concerns Over } \\
\text { Coach Education } \\
\text { Structure }\end{array}$ & $\begin{array}{l}\text { s. Competition } \\
\text { jurisdiction issues }\end{array}$ \\
\hline c. Commercial & g. ACs Ambiguity & 1. Key Hires as a & t. Low Levels of \\
\hline Sponsorship Volatility & $\begin{array}{l}\text { Over 'Full-Time' } \\
\text { Athletes }\end{array}$ & $\begin{array}{l}\text { Significant Change of } \\
\text { Ethos }\end{array}$ & Domestic Competition \\
\hline \multirow{9}{*}{$\begin{array}{l}\text { d. ACs ambiguous } \\
\text { attitude towards CSCs }\end{array}$} & h. AC struggling with & m. Volunteer Ethos & u. Suitable \\
\hline & low federal funding & Prevalence & $\begin{array}{l}\text { Competition for Elite } \\
\text { Athletes issue }\end{array}$ \\
\hline & \multirow{7}{*}{$\begin{array}{l}\text { i. Restricted Athlete } \\
\text { funding to AAP }\end{array}$} & n. Christie Report & v. Competing \\
\hline & & (2001) as a Catalyst & Competition Schedules \\
\hline & & $\begin{array}{l}\text { o. sport Science } \\
\text { Legitimization in } 1988\end{array}$ & $\begin{array}{l}\text { w. Elite + Sub-Elite } \\
\text { Competition divide }\end{array}$ \\
\hline & & p. Sport Science & x. No Comprehensive \\
\hline & & Problematic for AC & Competition Structure \\
\hline & & q. Sport Science & y. AC emerging from a \\
\hline & & Internally Developed & Policy Void \\
\hline
\end{tabular}

